\title{
Super Twisting Algorithm Direct Power Control of DFIG Using Space Vector Modulation
}

\author{
F. Mazouz, S. Belkacem
}

\begin{abstract}
This paper presents a comparative study of two approaches for the direct power control (DPC) of doubly-fed induction generator (DFIG) based on wind energy conversion system (WECS). Vector Control (VC) and Sliding Mode Control (SMC). The simulation results of the DFIG of $5 \mathrm{KW}$ in the presence of various uncertainties were carried out to evaluate the capability and robustness of the proposed control scheme. The (SMC) strategy is the most appropriate scheme with the best combination such as reducing high powers ripple, diminishing steady-state error in addition to the fact that the impact of machine parameter variations does not change the system performance.
\end{abstract}

\section{INTRODUCTION}

Doubly fed induction generators (DFIG) are used widely in wind generation systems because of their variable speed operation [1-9]. The control of the instantaneous active and reactive powers of the stator is obtained by regulating the decoupled rotor currents, using proportional-integral regulators (PI) [10-12]. Nevertheless, this control structure strongly depends on the parameters of the machine, uses multiple loops and requires many computational efforts to guarantee the stability of the structure over the entire speed.

Many methods have been presented to remedy these problems. The direct torque controls (DTC) [13], [15] or direct power control (DPC) has been introduced [16-21]. In the recent period, DPC strategies have also been developed to control DFIG systems. DPC provides a fast dynamic response, a simple structure. The basic DPC suffers from a great ripple in currents, active and reactive powers. In addition, the variable switching frequency is another disadvantage of this method.

Several researchers have focused on the progress of DPC techniques that operate at a variable switching frequency [22]. Harmonic filters and complicated AC power converters are a consequence of the use of the variable switching frequency.

Authors in references [23] and [24] are interested in DPC without zero voltage sequences; a first choice is to use only active sequences. This choice has the advantage of simplicity and avoids the randomness related to the direction of variation of the powers when applying a zero sequence. Indeed, the use of these voltage sequences makes it possible to reduce the switching frequency.

Variable Structure Control (VSC) is, by its nature, a nonlinear control; it is based on the switching of functions of state variables, used to create a sliding variety or hypersurface, whose purpose is to force the dynamics of the

F. Mazouz is with the Electrical Engineering Department, University of batna2, Algeria; (e-mail:f.mazouz@yahoo.fr).

S. Belkacem is with the Electrical Engineering Department, University of batna2, Algeria (e-mail: belkacem_sebti@yahoo.fr). system to correspond with that defined by the equation of the hypersurface. When the state is maintained on this hypersurface, the system is in sliding mode. Its dynamics are then insensitive to external and parametric disturbances as long as the conditions of the sliding regime are ensured.

Sliding mode control (SMC), because of its robustness to external uncertainties and disturbances, can be applied to uncertain and disturbed nonlinear systems. Several works have been elaborated on SMC. The combination of the sliding mode control and the DPC makes it possible to reduce the ripples of the powers. Disadvantage of this association is that the use of the saturation function introduces a static error which persists [21-22].

In practice, the use of the SMC has been limited for a long time by the oscillations related to the commutations of the control, which can be manifested on the enslaved quantities. Since then, many solutions have been proposed to reduce these oscillations: increase of the switching frequency, continuous control in a band around the slip variety, decomposition of the control into a low frequency DC component, a discontinuous high control frequency and the method of the boundary layer where the discontinuous component of the control is replaced in the vicinity of the sliding hypersurface by a continuous function.

SMC, because of its robustness to external uncertainties and disturbances, can be applied to uncertain and disturbed nonlinear systems. Several works have been elaborated on SMC [26-27].

In references [23-24] a model predictive direct power control (MP-DPC) with power compensation is presented. In this study, although the network is unbalanced, the current waveform is in sinusoidal shape, the active and reactive power ripple and torque oscillations are reduced in order to improve the performance of DFIG.

The main idea of Predictive Control (MPC) is based on the use of a model of the system to be controlled to predict its output over at a certain horizon, the development of an optimal sequence of future orders satisfying the constraints and minimizing a cost function, the application of the first element of the optimal sequence on the system and the repetition of the complete procedure at the next sampling period and then the advantage of the MPC then involves the resolution of a dimension optimization problem finished at each sampling period.

The main disadvantage of the MPC command is the execution time, in the design stage of the MPC command. It is desirable to be able to predict the dynamic behavior and for this it is necessary to have a precise knowledge of the constituents of the process. However, in real problems, the difficulty is that often there is no precise model of the process. This can have multiple reasons: the prior information is incomplete, the characteristics vary with time or unknown disturbances affect the process to be controlled. 
Fig. 1 displays the proposed control diagram for WECS based on DFIG. In this diagram, the reactive and active powers are controlled directly by switching the voltage vectors to the rotor side terminals using RSC.

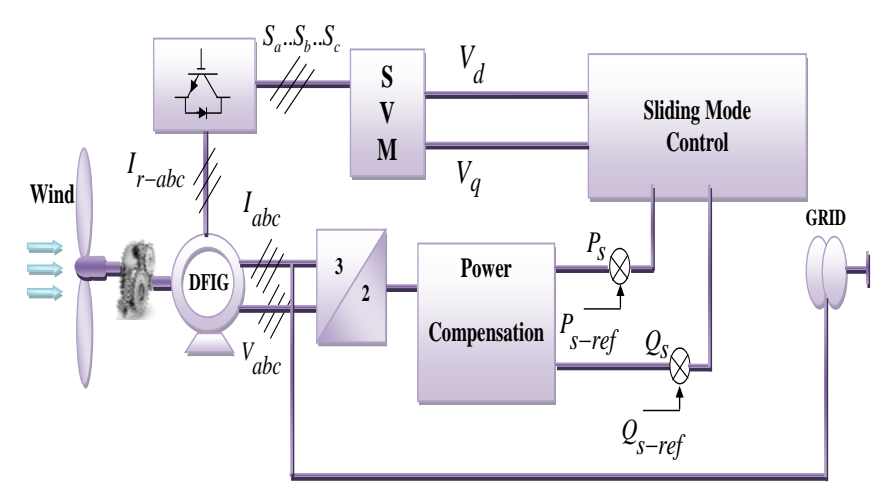

Figure 1. Structural control of the wind chain.

\section{DYNAMIQUE BEHAVIOR OF A DFIG}

The DFIG dynamic equations in the reference d-q form can be written as follows [11]. The voltages equations are given by:

$$
\left\{\begin{array}{l}
\mathrm{V}_{\mathrm{ds}}=\mathrm{R}_{\mathrm{s}} \mathrm{I}_{\mathrm{ds}}+\frac{\mathrm{d} \varphi_{\mathrm{ds}}}{\mathrm{dt}}-\omega_{\mathrm{s}} \varphi_{\mathrm{qs}} \\
\mathrm{V}_{\mathrm{qs}}=\mathrm{R}_{\mathrm{s}} \mathrm{I}_{\mathrm{qs}}+\frac{\mathrm{d} \varphi_{\mathrm{qs}}}{\mathrm{dt}}+\omega_{\mathrm{s}} \varphi_{\mathrm{ds}} \\
\mathrm{V}_{\mathrm{dr}}=\mathrm{R}_{\mathrm{r}} \mathrm{I}_{\mathrm{dr}}+\frac{\mathrm{d} \varphi_{\mathrm{dr}}}{\mathrm{dt}}-\omega_{\mathrm{r}} \varphi_{\mathrm{qr}} \\
\mathrm{V}_{\mathrm{qr}}=\mathrm{R}_{\mathrm{r}} \mathrm{I}_{\mathrm{qr}}+\frac{\mathrm{d} \varphi_{\mathrm{qr}}}{\mathrm{dt}}+\omega_{\mathrm{r}} \varphi_{\mathrm{dr}}
\end{array}\right.
$$

The flux equations are given by:

$$
\left\{\begin{array}{l}
\varphi_{\mathrm{ds}}=\mathrm{L}_{\mathrm{s}} \mathrm{I}_{\mathrm{ds}}+\mathrm{MI}_{\mathrm{dr}} \\
\varphi_{\mathrm{qs}}=\mathrm{L}_{\mathrm{s}} \mathrm{I}_{\mathrm{qs}}+\mathrm{MI}_{\mathrm{qr}} \\
\varphi_{\mathrm{dr}}=\mathrm{L}_{\mathrm{r}} \mathrm{I}_{\mathrm{dr}}+\mathrm{MI}_{\mathrm{ds}} \\
\varphi_{\mathrm{qr}}=\mathrm{L}_{\mathrm{r}} \mathrm{I}_{\mathrm{qr}}+\mathrm{MI}_{\mathrm{qs}}
\end{array}\right.
$$

The torque equation is represented as follows:

$$
\mathrm{T}_{\mathrm{em}}=\mathrm{p} \frac{\mathrm{M}}{\mathrm{L}_{\mathrm{s}}}\left(\mathrm{I}_{\mathrm{qr}} \varphi_{\mathrm{ds}}-\mathrm{I}_{\mathrm{dr}} \varphi_{\mathrm{qs}}\right)
$$

The supplied active and reactive powers are defined as follows:

$$
\begin{aligned}
& P_{\mathrm{s}}=\left(\mathrm{V}_{\mathrm{ds}} \mathrm{I}_{\mathrm{ds}}+\mathrm{V}_{\mathrm{qs}} \mathrm{I}_{\mathrm{qs}}\right) \\
& \mathrm{Q}_{\mathrm{s}}=\left(\mathrm{V}_{\mathrm{qs}} \mathrm{I}_{\mathrm{ds}}-\mathrm{V}_{\mathrm{ds}} \mathrm{I}_{\mathrm{qs}}\right)
\end{aligned}
$$

\section{SPACE VECTOR MODULATION OF A DFIG}

Fig. 2 represents the voltage vectors, produced by a threephase PWM inverter divide the spatial vector plane into six sections.

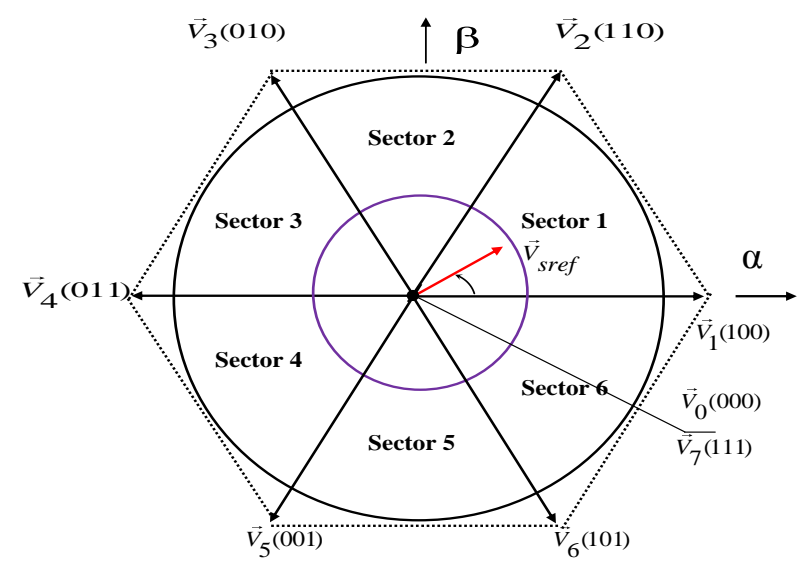

Figure 2. The diagram of voltage space vectors

The SVM techniques consists of reconstructing the reference voltage $\mathrm{V}_{\text {sref }}$ by the adjacent voltage vectors and a null vector. Take an example, in the first sector, $\overline{\mathrm{V}}_{\text {sref }}$ is a synthesized voltage space vector and expressed by:

$$
\overline{\mathrm{V}}_{\mathrm{s} \mathrm{ref}} \mathrm{T}_{\mathrm{s}}=\overline{\mathrm{V}}_{0} \mathrm{~T}_{0}+\overline{\mathrm{V}}_{1} \mathrm{~T}_{1}+\overline{\mathrm{V}}_{2} \mathrm{~T}_{2}
$$

with: $\mathrm{T}_{\mathrm{s}}=\mathrm{T}_{0}+\mathrm{T}_{1}+\mathrm{T}_{2}$

where, $\mathrm{T}_{0}, \mathrm{~T}_{1}$ and $\mathrm{T}_{2}$ is the work time of basic space voltage vectors $\overline{\mathrm{V}}_{0}, \overline{\mathrm{V}}_{1}$ and $\overline{\mathrm{V}}_{2}$ respectively.

\section{VECTOR CONTROL STRATEGY OF DFIG}

The goal of the VC of DFIG is to obtain a decoupled control of the active and reactive powers as in DC machines, [6]. Indirect vector control is the better frequently used because of its simplicity and low cost of implementation.

The vector control of DFIG consists in making $\varphi_{\mathrm{qs}}=0$, and $\varphi_{\mathrm{ds}}=\varphi_{s}$. Where $\varphi_{\mathrm{s}}$ the reference flux.

By applying this principle into the equation (3), the torque equation is presented as follows:

$$
\mathrm{T}_{\mathrm{em}}=\mathrm{p} \frac{\mathrm{M}}{\mathrm{L}_{\mathrm{s}}}\left(\mathrm{I}_{\mathrm{qr}} \varphi_{\mathrm{s}}\right)
$$

The adjustment of the equations (1) and (2) gives the rotor voltages expression according to the rotor currents by:

$$
\left\{\begin{array}{l}
\mathrm{V}_{\mathrm{dr}}=\mathrm{R}_{\mathrm{r}} \mathrm{I}_{\mathrm{dr}}+\sigma \mathrm{L}_{\mathrm{r}} \cdot \frac{\mathrm{dI} \mathrm{dr}_{\mathrm{d}}}{\mathrm{dt}}-\mathrm{g} \omega_{\mathrm{s}} \sigma \mathrm{L}_{\mathrm{r}} \cdot \mathrm{I}_{\mathrm{qr}} \\
\mathrm{V}_{\mathrm{qr}}=\mathrm{R}_{\mathrm{r}} \mathrm{I}_{\mathrm{qr}}+\sigma \mathrm{L}_{\mathrm{r}} \cdot \frac{\mathrm{dI} \mathrm{qr}}{\mathrm{dt}}-\mathrm{g} \omega_{\mathrm{s}} \cdot \sigma \mathrm{L}_{\mathrm{r}} \cdot \mathrm{I}_{\mathrm{dr}}+\mathrm{g} \frac{\mathrm{M} \cdot \mathrm{V}_{\mathrm{s}}}{\mathrm{L}_{\mathrm{s}}}
\end{array}\right.
$$

With: $\sigma=1-\frac{\mathrm{M}^{2}}{\mathrm{~L}_{\mathrm{s}} \mathrm{L}_{\mathrm{r}}}$

By neglecting the stator resistance $R_{s}$ we can deduce from the equation (7):

$$
\begin{aligned}
& \mathrm{V}_{\mathrm{ds}}=\frac{\mathrm{d} \varphi_{\mathrm{s}}}{\mathrm{dt}}=0 \\
& \mathrm{~V}_{\mathrm{qs}}=\mathrm{V}_{\mathrm{s}}=\omega_{\mathrm{s}} \varphi_{\mathrm{qs}}
\end{aligned}
$$


The active and reactive powers of the stator can be expressed as follows:

$$
\begin{gathered}
P_{\mathrm{s}}=-\left(\mathrm{V}_{\mathrm{s}} \frac{\mathrm{M}}{\mathrm{L}_{\mathrm{s}}} \mathrm{I}_{\mathrm{qr}}\right) \\
\mathrm{Q}_{\mathrm{s}}=\left(\frac{\mathrm{V}_{\mathrm{s}}^{2}}{\mathrm{~L}_{\mathrm{s}} \omega_{\mathrm{s}}}-\mathrm{V}_{\mathrm{s}} \frac{\mathrm{M}}{\mathrm{L}_{\mathrm{s}}} \mathrm{I}_{\mathrm{dr}}\right)
\end{gathered}
$$

In this method, the decoupling is done at the output of the regulators in rotor current with a return of the system. A cascaded loop control of the power and the rotor current for each axis, since it makes it possible to separately control the currents $\mathrm{I}_{\mathrm{dr}}$ and $\mathrm{I}_{\mathrm{qr}}$ and the powers $\mathrm{Q}_{\mathrm{s}}$ and $\mathrm{P}_{\mathrm{s}}$ in a closed loop.

\section{DESIGN OF SMC OF DFIG}

The method of sliding mode control, is a nonlinear control technique, it is characterized by the discontinuity of control at the passages by a switching surface called sliding surface. The sliding mode technique involves bringing the state path of a system to the sliding surface and causing it to switch by appropriate switching around it to the point of equilibrium. In summary, a sliding speed control is divided into two parts:

-Determination of a state space region such that once the system is in that region, it has the desired behavior;

-Definition of a control law that leads the system to this region of the state space;

The design of the sliding mode controller systematically takes into account the problems of stability and good performance in its behavior, achieved mainly in three complementary steps defined by [26]:

- The choice of the sliding surface;

-Establishment of the conditions of existence sliding regime;

- Determination of the control law;

For a non-linear system, the design of the control system is given by following equation:

$$
\dot{x}=f(x, t)+f(x, t)+u(x, t)
$$

Or:

$X \epsilon R^{n}:$ is the state vector,

$u \in R^{m}$ :is the command vector.

$f(x, t) \epsilon R^{n}, B(x, t) \epsilon R^{n \times m}$.

To determine the sliding surface we have the general equation form:

$$
\mathrm{S}(\mathrm{x})=\left(\frac{\mathrm{d}}{\mathrm{dt}}+\lambda_{\mathrm{s}}\right)^{\mathrm{n}-1} \mathrm{e}(\mathrm{x})
$$

with:

$S(x)$ : is an linear differential equation whose response " $\mathrm{e}$ " tends to zero for a correct choice of gain $\lambda_{s}$ this is the objective of the command.

$\lambda_{s}$ : Positive coefficient.

$e$ : Deviation (error) of the variable to be adjusted n: System order,

The conditions of existence and convergence are the criteria that allow the different dynamics of the system to converge towards the sliding surface and to remain there independently of the disturbance. There are two types of conditions that are:

- The discrete switching function: $\mathrm{S}(\mathrm{x}) . \dot{\mathrm{S}}(\mathrm{x})<0$

- The Lyapunov function: $\mathrm{V}(\mathrm{x})>0$

To guarantee the attraction of the variable to be controlled to its reference value, the idea is to choose a scalar function $\mathrm{S}$ (x) to design a command ' $\mathrm{u}$ ' such that the square of the surface corresponds to a function of Lyapunov:

$$
\mathrm{v}(\mathrm{x})=\frac{1}{2} \mathrm{~S}^{2}(\mathrm{x})
$$

Its derivative is:

$$
\mathrm{v}(\dot{\mathrm{x}})=\mathrm{S}(\mathrm{x}) \dot{\mathrm{S}}(\mathrm{x})
$$

To determine the control law the structure of a controller by sliding mode has two parts:

$$
\mathrm{u}=\mathrm{u}_{\mathrm{eq}}+\mathrm{u}_{\mathrm{n}}
$$

The derivative of the surface $\mathrm{S}(\mathrm{x})$ is:

$$
\dot{\mathrm{S}}(\mathrm{x})=\frac{\partial \mathrm{S}}{\partial \mathrm{t}}=\frac{\partial \mathrm{S}}{\partial \mathrm{x}} \cdot \frac{\partial \mathrm{x}}{\partial \mathrm{t}}
$$

By replacing the expressions (14) and (15) in the expression (16), we find:

$$
\dot{\mathrm{S}}(\mathrm{x})=\frac{\partial \mathrm{S}}{\partial \mathrm{x}}\left(\mathrm{f}(\mathrm{x}, \mathrm{t})+\mathrm{B}(\mathrm{x}, \mathrm{t}) \cdot \mathrm{u}_{\mathrm{eq}}(\mathrm{x}, \mathrm{t})\right)+\frac{\partial \mathrm{S}}{\partial \mathrm{x}} \mathrm{B}(\mathrm{x}, \mathrm{t}) \cdot u_{n}
$$

During the sliding mode and the steady state, the surface is zero, and consequently its derivative and the discontinuous part are also zero. From which we deduce the expression of the equivalent order [27]:

$$
\mathrm{u}_{\mathrm{eq}}=-\frac{\partial \mathrm{S}}{\partial \mathrm{t}} \cdot \mathrm{f}(\mathrm{x}, \mathrm{t}) \cdot\left(\frac{\partial \mathrm{S}}{\partial \mathrm{x}} \cdot \mathrm{B}(\mathrm{x}, \mathrm{t})\right)^{-1}
$$

So that the equivalent order can take a finite value, it is necessary that:

$$
\dot{\mathrm{S}}(\mathrm{x})=\frac{\partial \mathrm{S}}{\partial \mathrm{x}} \cdot \mathrm{B}(\mathrm{x}, \mathrm{t}) \cdot \mathrm{u}_{\mathrm{n}} \neq 0
$$

Replacing the equivalent command by its expression in the expression (19), we find the new expression of the derivative of the surface:

$$
\dot{\mathrm{S}}(\mathrm{x})=\frac{\partial \mathrm{S}}{\partial \mathrm{x}} \cdot \mathrm{B}(\mathrm{x}, \mathrm{t}) \cdot \mathrm{u}_{\mathrm{n}}
$$

Where the attractiveness condition $\mathrm{S}(\mathrm{x}) . \dot{\mathrm{S}}(\mathrm{x})<0$ becomes:

$$
\dot{\mathrm{S}}(\mathrm{x})=\frac{\partial \mathrm{S}}{\partial \mathrm{x}} \cdot \mathrm{B}(\mathrm{x}, \mathrm{t}) \cdot \mathrm{u}_{\mathrm{n}}<0
$$

In order to satisfy this condition, the sign of $u_{n}$ must be opposed to that of $S(x) \cdot \frac{\partial S}{\partial x} B(x, t)$

The discrete command in sliding mode can take the following expression:

$$
\mathrm{u}_{\mathrm{n}}=\mathrm{k} \cdot \operatorname{sign}(\mathrm{S}(\mathrm{x}, \mathrm{t}))
$$

\section{A. Active power control}

The expression of the control surface of the active power has the form: 


$$
\mathrm{S}(\mathrm{P})=\mathrm{P}_{\mathrm{s}-\mathrm{ref}}-\mathrm{P}_{\mathrm{S}}
$$

The derivative of the surface is:

$$
\dot{\mathrm{S}}(\mathrm{P})=\dot{\mathrm{P}}_{\mathrm{s}-\mathrm{ref}}-\dot{\mathrm{P}}_{\mathrm{S}}
$$

We replace the expression of the active power (9) in (24):

$$
\dot{\mathrm{S}}(\mathrm{P})=\left(\dot{\mathrm{P}}_{\mathrm{s}-\mathrm{ref}}-\mathrm{V}_{\mathrm{s}} \frac{\mathrm{M}}{\mathrm{L}_{\mathrm{s}}} \dot{\mathrm{I}}_{\mathrm{qr}}\right)
$$

We derive the expression of the current $\dot{I}_{q r}$ from the equation of the voltage $V_{q r}(7)$

$$
\dot{\mathrm{I}}_{\mathrm{qr}}=-\frac{1}{\sigma}\left(\frac{1}{\mathrm{~T}_{\mathrm{r}}}+\frac{\mathrm{M}^{2}}{\mathrm{~L}_{\mathrm{s}} \mathrm{T}_{\mathrm{s}} \mathrm{L}_{\mathrm{r}}}\right) \mathrm{I}_{\mathrm{qr}}-\mathrm{g} \omega_{\mathrm{s}} \mathrm{I}_{\mathrm{dr}}+\frac{1}{\sigma \mathrm{L}_{\mathrm{r}}} \mathrm{V}_{\mathrm{qr}}
$$

With: $\sigma=1-\frac{M^{2}}{L_{s} L_{r}} ; T_{r}=\frac{L_{r}}{R_{r}} ; g=\frac{W_{s}-W}{W_{s}}$

Then:

$$
\begin{aligned}
\dot{\mathrm{S}}(\mathrm{P}) & =\dot{\mathrm{P}}_{\mathrm{s}-\mathrm{ref}}-\mathrm{V}_{\mathrm{s}} \frac{\mathrm{M}}{\mathrm{L}_{\mathrm{s}} \mathrm{L}_{\mathrm{r}} \sigma} \cdot\left(\mathrm{V}_{\mathrm{qr}}-\mathrm{R}_{\mathrm{r}} \mathrm{I}_{\mathrm{qr}}-\mathrm{g} \frac{\mathrm{MV}_{\mathrm{s}}}{\mathrm{L}_{\mathrm{s}}}\right. \\
& \left.-\mathrm{g} \omega_{\mathrm{s}} \mathrm{L}_{\mathrm{r}} \sigma \mathrm{I}_{\mathrm{dr}}\right)
\end{aligned}
$$

Hence the expression of $V_{q r}=V_{q r-e q}+V_{q r-n}$

Replacing this expression in equation (27), we find:

$$
\begin{aligned}
\dot{S}(P) & =\dot{P}_{s-r e f}-V_{s} \frac{M}{L_{s} L_{r} \sigma} \cdot\left(\left(\mathrm{V}_{q r-e q}+V_{q r-n}\right)\right)-\mathrm{R}_{r} I_{q r} \\
& \left.-g \frac{M V_{s}}{L_{s}}-g \omega_{s} L_{r} \sigma I_{d r}\right)
\end{aligned}
$$

During the slip mode and in steady state, we have:

$$
\mathrm{S}(\mathrm{P})=0, \dot{\mathrm{S}}(\mathrm{P})=0 \text { et } \mathrm{V}_{\mathrm{qr}-\mathrm{n}}=0
$$

From the previous equation, we obtain the equivalent command quantity $\mathrm{V}_{\text {qreq }}$ which is written:

$$
\mathrm{V}_{\mathrm{qr}-\mathrm{eq}}=\frac{\mathrm{L}_{\mathrm{s}} \mathrm{L}_{\mathrm{r}} \sigma}{\mathrm{MV}_{\mathrm{s}}} \dot{\mathrm{P}}_{\mathrm{s} \text {-ref }}-\left(\mathrm{R}_{\mathrm{r}} \mathrm{I}_{\mathrm{qr}}+\mathrm{g} \frac{\mathrm{MV}}{\mathrm{L}_{\mathrm{s}}}+\mathrm{g} \omega_{\mathrm{s}} \mathrm{L}_{\mathrm{r}} \sigma \mathrm{I}_{\mathrm{dr}}\right)
$$

And:

$$
\mathrm{V}_{\mathrm{qr}-\mathrm{n}}=\mathrm{k}_{\mathrm{vqr}-\mathrm{n}} \cdot \operatorname{sign}(\mathrm{S}(\mathrm{P}))
$$

With:

$\mathrm{K}_{\mathrm{Vqr}-\mathrm{n}}:$ is a positive gain.

\section{B. Control of the reactive power}

The expression of the control surface of the reactive power has the form:

$$
\mathrm{S}(\mathrm{Q})=\mathrm{Q}_{\mathrm{s}-\mathrm{ref}}-\mathrm{Q}_{\mathrm{s}}
$$

The derivative of the surface is:

$$
\dot{\mathrm{S}}(\mathrm{Q})=\dot{\mathrm{Q}}_{\mathrm{s}-\mathrm{ref}}-\dot{\mathrm{Q}}_{\mathrm{S}}
$$

Replace the expression of the reactive power (10)

$$
\dot{\mathrm{S}}(\mathrm{Q})=\left(\dot{\mathrm{Q}}_{\mathrm{s}-\mathrm{ref}}-\mathrm{V}_{\mathrm{s}} \frac{\mathrm{M}}{\mathrm{L}_{\mathrm{s}}} \dot{\mathrm{I}}_{\mathrm{dr}}\right)
$$

We derive the expression of the current $I_{d r}$ from the equation of the voltage $\mathrm{V}_{\mathrm{dr}}(7)$

$$
\dot{\mathrm{I}}_{\mathrm{dr}}=-\frac{1}{\sigma \mathrm{T}_{\mathrm{r}}} \mathrm{I}_{\mathrm{dr}}+\mathrm{g} \omega_{\mathrm{s}} \mathrm{I}_{\mathrm{qr}}+\frac{1}{\sigma \mathrm{L}_{\mathrm{r}}} \mathrm{V}_{\mathrm{dr}}
$$

Then:

$$
\dot{S}(Q)=\dot{Q}_{s-r e f}-V_{s} \frac{M}{L_{s} L_{r} \sigma} \cdot\left(V_{d r}-R_{r} I_{d r}-g \omega_{s} L_{r} \sigma I_{q r}\right)
$$

Hence the expression of $\mathrm{V}_{\mathrm{dr}}=\mathrm{V}_{\mathrm{dr}-\mathrm{eq}}+\mathrm{V}_{\mathrm{dr}-\mathrm{n}}$

Replacing this expression in equation (35), we find:

$$
\begin{aligned}
& \dot{\mathrm{S}}(\mathrm{Q})=\dot{\mathrm{Q}}_{\mathrm{s}-\mathrm{ref}}-\mathrm{V}_{\mathrm{s}} \frac{\mathrm{M}}{\mathrm{L}_{\mathrm{s}} \mathrm{L}_{\mathrm{r}} \sigma} \cdot\left(\left(\mathrm{V}_{\mathrm{dr}-\mathrm{eq}}+\mathrm{V}_{\mathrm{dr}-\mathrm{n}}\right)-\mathrm{R}_{\mathrm{r}} \mathrm{I}_{\mathrm{dr}}\right. \\
& \left.-\mathrm{g} \omega_{\mathrm{s}} \mathrm{L}_{\mathrm{r}} \sigma \mathrm{I}_{\mathrm{qr}}\right)
\end{aligned}
$$

During sliding mode and steady state, we have:

$$
\mathrm{S}(\mathrm{Q})=0, \quad \dot{S}(\mathrm{Q})=0 \text { et } \mathrm{V}_{\text {rd-n }}=0
$$

Which we deduce:

$$
\left.V_{\mathrm{dr}-\mathrm{eq}}=\frac{\mathrm{L}_{\mathrm{s}} \mathrm{L}_{\mathrm{r}} \sigma}{\mathrm{MV}_{\mathrm{s}}} \dot{\mathrm{Q}}_{\mathrm{s}-\mathrm{ref}}-\mathrm{R}_{\mathrm{r}} \mathrm{I}_{\mathrm{dr}}-\mathrm{g} \omega_{\mathrm{s}} \mathrm{L}_{\mathrm{r}} \sigma \mathrm{I}_{\mathrm{qr}}\right)
$$

and:

$$
\mathrm{V}_{\mathrm{dr}-\mathrm{n}}=\mathrm{k}_{\mathrm{vdr}-\mathrm{n}} \cdot \operatorname{sign}(\mathrm{S}(\mathrm{Q}))
$$

$K_{V d r-n}$ : is a positive gain.

The proposed SMC, which is designed to control active and reactive powers of the DFIG, is shown in Figure. 3.

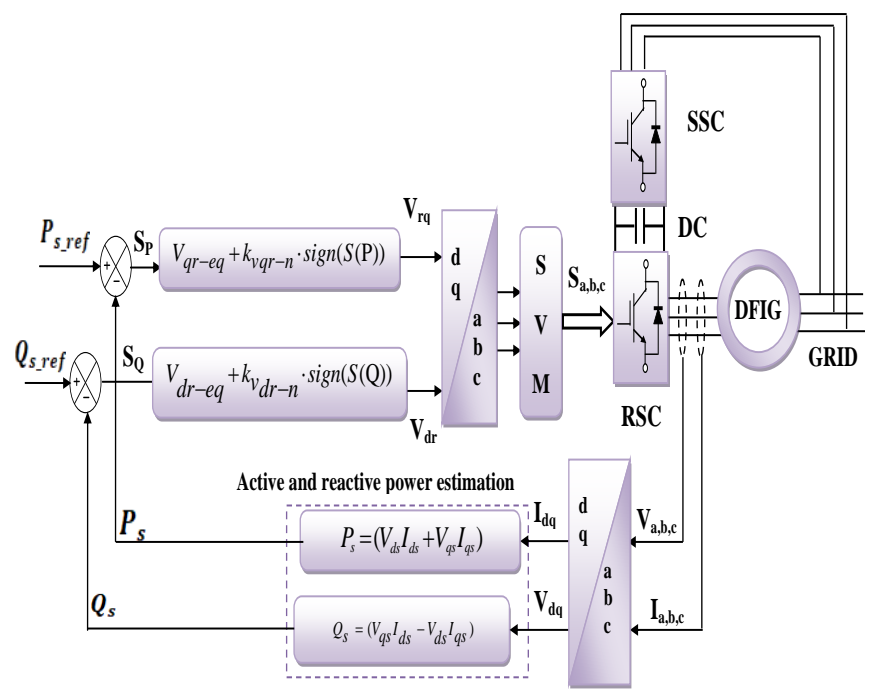

Figure 3. Block diagram of the DFIG with SMC.

\section{SimULATION RESULTS}

In order to show the feasibility of the proposed SMC, simulation studies of the drive system based on the DFIG 
were carried out using MATLAB/Simulink. The real parameters of a wind turbine and a DFIG are presented in Table.1.

\section{A. Simulation results without parametric variation}

In Fig. 4 the active powers produced by the DFIG controlled by VC, SMC is presented. In this figure, it can be noticed that the ripple is not the same for the two techniques. It is clear that the VC suffer from two problems: steady state error and high active powers ripple. In the other hand, the SMC provides almost perfect behaviour in tracking performance compared with the VC. The stator reactive powers illustrated in Fig. 5 track the irreverence values very well; we can view that SMC shows a better performance than VC. Using SMC the stator reactive powers oscillations are lower, while with VC the dynamic is slower, due to the presence of the PI regulators and control loops.

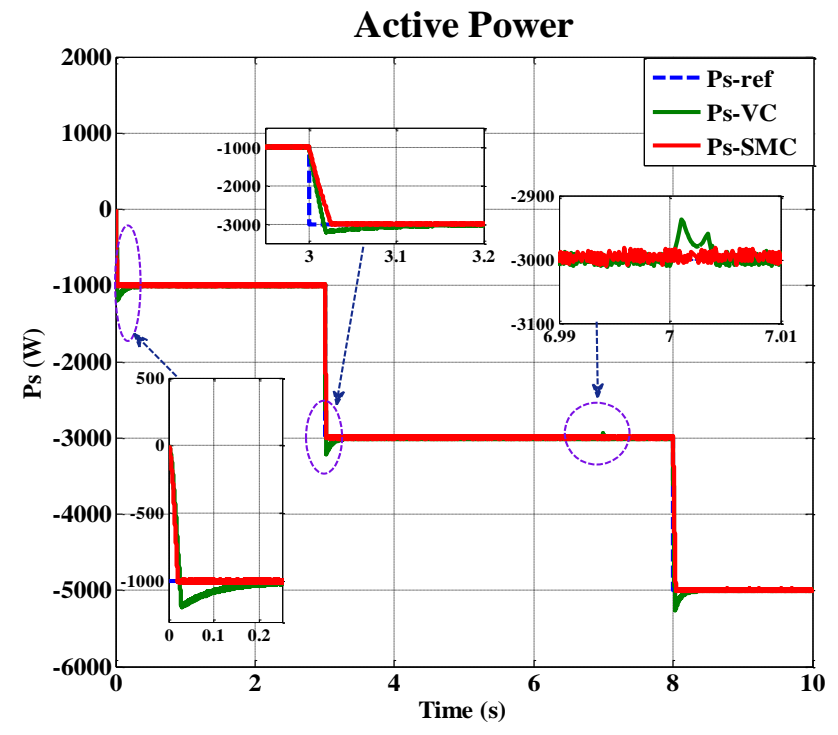

Figure 4. Active power response

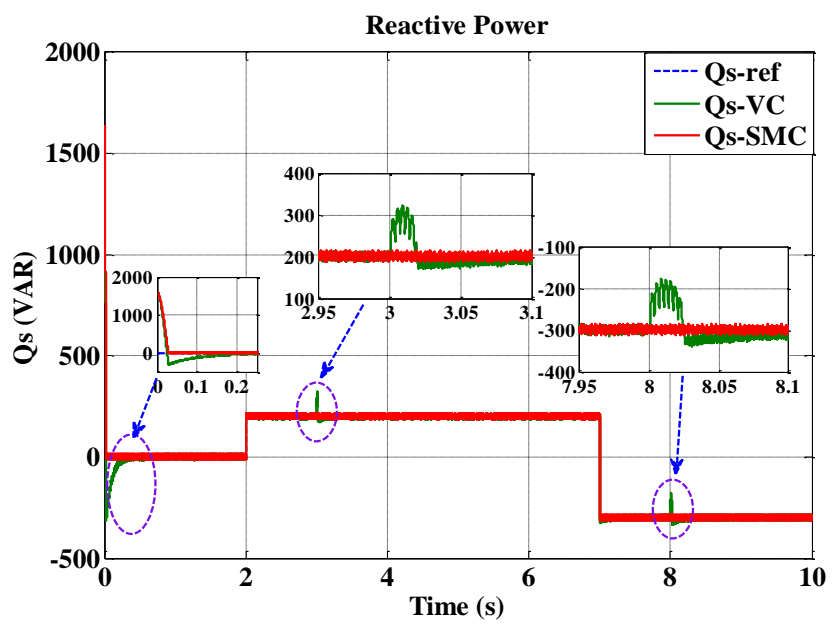

Figure 5. Reactive power response

Fig. 6. the stator current behaviour is sinusoidal and it is similar for both strategies, the system is operating at rated conditions. It can be observed that the current ripple has also a notable reduction in SMC compared to the other VC.

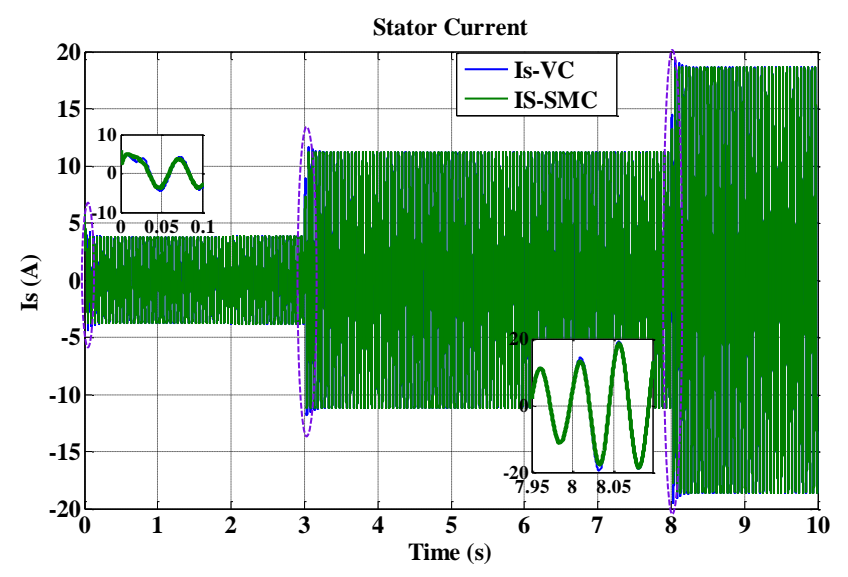

Figure 6. Stator current

B. Simulation results with parametric variation $+150 \%$ on $R_{r}$ and $L_{r}$

To evaluate the influence of DFIG parameters variations on the performance of the proposed SMC, the rotor resistance parameter sensitivity is tested for the two schemes for $+150 \%$ variation in $R_{r}$ and $L_{r}$ at time $t=8 \mathrm{~s}$, The active and reactive powers are shown in Fig. 7 . It can be observed from these figures that the $\mathrm{VC}$ schemes have a considerable error due to $L_{r}$ and $R_{r}$ variation. However remarkable improvements are achieved by SMC control approach.

Active power (W)

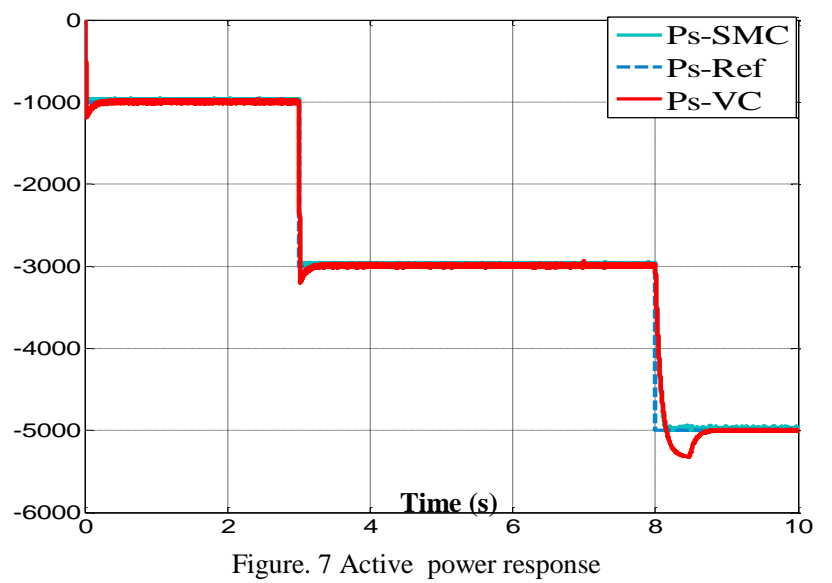

VII. CONCLUSION

In this paper, a comparative study between the conventional vector control and sliding mode control has been presented. However, in order to test the influence of DFIG parameter variations on the performances of the proposed (SMC), the rotor resistance parameter sensitivity is tested for the three schemes for $+150 \%$ variations in rotor resistance; it was rigorously shown that the SMC is robust and able to reject the influences of the variations of system parameters. The proposed method can be considered as an alternative solution to the control of DFIG.

Appendix

TABLE 1 DFIG and wind turbine parameters

\begin{tabular}{|l|l|}
\hline DFIG parameters & Wind Turbine parameters
\end{tabular}




\begin{tabular}{|c|c|c|c|}
\hline Rated power, Pn & $5 \mathrm{KW}$ & Blade radius, $\mathrm{R}$ & 3.1915 \\
\hline Stator rated voltage, Vs & $220 / 380 \mathrm{~V}$ & Number of blades & 2 \\
\hline Rates current, In & $16 \mathrm{~A}$ & Gearbox ratio, $\mathrm{G}$ & 1 \\
\hline Stator rated frequency, $\mathrm{f}$ & $50 \mathrm{~Hz}$ & $\begin{array}{c}\text { Moment of } \\
\text { inertia, } \mathrm{J}\end{array}$ & $\begin{array}{l}7.68 \\
\text { Kg.m }\end{array}$ \\
\hline Stator inductance, Ls & $0.094 \mathrm{H}$ & $\begin{array}{c}\text { Viscous friction } \\
\text { coefficient, } f\end{array}$ & $0 \mathrm{~N} \cdot \mathrm{m} \cdot \mathrm{s}^{-1}$ \\
\hline Rotor inductance, $\mathrm{Lr}$ & $0.088 \mathrm{H}$ & & \\
\hline Mutual inductance, $\mathrm{M}$ & $0.0135 \mathrm{H}$ & & \\
\hline Stator resistance, Rs & $0.95 \Omega$ & & \\
\hline Rotor resistance, $\mathrm{Rr}$ & $1.08 \Omega$ & & \\
\hline Number of pair poles, $\mathrm{P}$ & 3 & & \\
\hline
\end{tabular}

\section{REFERENCES}

[1] T. Ackermann, Wind Power in Power Systems. John Wiley and Sons, 2005.

[2] H. Wanger, J. Mathur, Introduction to wind energy systems. Green Energy and Technology, Berlin Heidelberg: Springer, 2013.

[3] M. Tazil, V. Kumar, S. Kong, Three-Phase doubly fed induction generator: An over view, IET Electric Power Application, pp. 75-89, 2009.

[4] R. Cárdenas, Peña R, Alepuz S, Asher G. Overview of control systems for the operation of DFIGs in wind energy applications, IEEE Trans Ind Electron, Vol. 7, 2776-98, 2013.

[5] S. Chemidi, M. Meliani, M. C. Benhabib, The Comparative Study between Back to Back and the Matrix Structure for the Wind Turbine Based on DFIG International Journal of Renewable Energy Research, Vol. 5, No. 3, pp. 758-765, 2015.

[6] F. Amrane, A. Chaiba, Babes, B.E, Mekhilef, S. Design and Implementation of High Performance Field Oriented Control for Grid Connected Doubly Fed Induction Generator Via Hysteresis Rotor Current Controller, Rev. Roum. Sci. Techn. - Électrotechn. Et Énerg., 61, 4, pp. 319-324, 2016.

[7] M. Depenbrock, Direct self-control (DSC) of inverter-fed induction machine, IEEE Trans. Power Electron., PE-3, pp. 420-429, 1988.

[8] T. Takahashi, I. Noguchi, A new quick-response and high-efficiency control of an induction motor, IEEE Trans. Industry Applications, IA22, Vol. 5, pp. 820-827, 1986

[9] S. Tamalouzt, I. Kassa. R. Toufik. A. Rachid, Direct Torque Control of Wind Turbine Driven Doubly Fed Induction Generator, Rev. Roum. Sci. Techn. Électrotechn. EtÉnerg, Vol. 61, No. 3, pp. 244249, 2016.

[10] M. Arbaoui, A. Essadki, T. Nasser, H. Chalawane, Comparative Analysis of ADRC \& PI Controllers Used in Wind Turbine System Driving a DFIG, International Journal of Renewable Energy Research, Vol.7, No.4, pp.1817-1824, 2017.

[11] F. Mazouz, S. Belkacem, Y. Harbouche, R. Abdessemed, S. Ouchen, Active and Reactive Power Control of a DFIG For Variable Speed Wind Energy Conversion, IEEE 6thInternational conference on systems and control (ICSC'2017), Algeria, 2017.

[12] N. Mekkaoui, M.S. Naït-Saïd, Direct S-power control for a doubly fed induction generator, Rev. Roum. Sci. Techn. Électrotechn. Et Énerg. Vol. 62, No. 4, pp. 365-370, Bucharest, 2017.
[13] M. Fdaili, A. Essadki, T. Nasser, Comparative Analysis Between Robust SMC \& Conventional PI Controllers Used in WECS Based on DFIG, International Journal of Renewable Energy Research, Vol. 7, No. 4, pp. 2152-2161. 2017.

[14] S. Lia, H. Wang, Y. Tian, A. Aitouch, Direct active and reactive power regulation of DFIG using sliding-mode control approach. IEEE Trans Energy Convers, Vol. 25, pp. 1028-39, 2010.

[15] F. Mazouz, S. Belkacem, Y. Harbouche, S. Ouchen R, Abdessemed Fuzzy control of a wind system based on the DFIG, 2017 International Conference on Artificial Intelligence in Renewable Energetic Systems IC-AIRES2017.

[16] M. Nadour, A. Essadki, T. Nasser, Comparative Analysis between PI \& Backstepping Control Strategies of DFIG Driven by Wind Turbine, International Journal of Renewable Energy Research, Vol. 7, No. 3, pp. 1308-1316, 2017.

[17] J. Zandzadeh, A. Vahedi, M., Mohammad , Improvement of direct power control of DFIG under unbalanced grid voltage condition, Electrical Power and Energy Systems, Vol. 59, pp. 58-65, 2014.

[18] D. Zhi, L. Xu, "Direct Power Control of DFIG With Constant Switching Frequency and Improved Transient Performance", IEEE Transactions on Energy Conversion, vol. 22, no. 1, pp. 110-118, March 2007.

[19] G. Xiao-Ming, S. Dan, H. Ben-Teng, H. Ling-Ling, Direct Power Control for Wind-Turbine Driven Doubly-Fed Induction Generator with Constant Switch Frequency, Proceeding of International Conference on Electrical Machines and Systems, Seoul, Korea, pp. 253-258, Oct. 8-11,2007.

[20] Z. Gadouche, B. Cheikh, T. Allaoui, B. Belabbas, Speed-Sensorless DFIG Wind Turbine for Power Optimization Using Fuzzy Sliding Mode Observer. International Journal of Renewable Energy Research, Vol. 7, No. 2, pp. 614-621, 2017.

[21] JJE. Slotine. Sliding controller design for nonlinear systems. Int J Control 1984; 40: 421-434.

[22] S. Lia, H. Wang, Y. Tian, A. Aitouch, Direct active and reactive power regulation of DFIG using sliding-mode control approach. IEEE TransEnergy Convers, Vol. 25, pp. 1028-39, 2010.

[23] N. Kalamian, M. VerijKazemi, S.A. Gholamian, Direct Power Control of DFIG By Using Nonlinear Model Predictive Controller, Asian Journal of Control, Vol. 18, No. 4, pp. 985-999, 2016.

[24] M. Mason, R. Kazemzadeh, M.R. Azizian, Model-based predictive direct power control of brushless doubly fed reluctance generator for wind power applications, Alexandria Engineering Journal, Vol. 55, pp. 2497-2507, 2016

[25] Y. Zhang, J. Hu, and J. Zhu, A novel three-Vectors-Based Predictive Direct Power Control of Doubly Fed Induction Generator for Wind Energy Applications, IEEE Energy conversion congress and exposition (ECCE), pp. 793-800,2012.

[26] M. A Mahboub, S. Drid, M. A. Sid, R. Cheikh, Sliding mode control of grid connected brushless doubly fed induction generator driven bywind turbine in variable speed, Int J Syst Assur Eng Manag,2016.

[27] A. Bourouina, A. Chaker, Z. Boudjema, A Djahbar, Comparative study between PI, RST and sliding mode controllers of a DFIG supplied by an AC-AC converter for wind energy conversion system, Carpathian Journal of Electronic and Computer Engineering, 2015, pp. 7-14. 